\title{
How to Support Vulnerable Citizens during the COVID-19 Lockdown: A Community Initiative from Ubiquitous Network Perspectives
}

\author{
Hiroko Oe ${ }^{1}$, Max Weeks ${ }^{2}$ \\ ${ }^{1}$ The Business School Bournemouth University, UK \\ ${ }^{2}$ The Brockenhurst College, UK \\ hoe@bournemouth.ac.uk, forestgate@nifty.com
}

\begin{abstract}
The current COVID-19 lockdown situation has had a negative impact on people's connectedness which also has an influence on the well-being of the citizens (Canady, 2020; Hare-Duke, 2019; Oe, 2020). The enhancement of human interaction and networking is a key topic to sustain people's health, and this has been on the emergent agenda during the current COVID-19 situation (Oe, 2020).To tackle this issue, one theory that could be employed is the efficacy of community members' engagement, as proposed by McMillian and Chavis (1986), who summarised a key 'sense of community' model. This model suggests four main dimensions should be strengthened to engage community members in supporting vulnerable people: a sense of belonging, an emotional connection, fulfilment of needs, and influence (Bermea et al., 2019).This conceptual paper aims to enhance the discussion of how best to support vulnerable isolated citizens during the COVID-19 lockdown situation. A proposition framework suggests actionable implications with tangible recommendations for the relevant stakeholders. The authors propose two key themes to be considered: (1) how to meet needs and provide support in the virtual network community, and (2) how to implement assistive technologies as a ubiquitous network paradigm as a community safety net for all.
\end{abstract}

Keywords

vulnerable citizens;

Covid-19; community

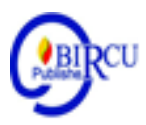

\section{Introduction}

COVID-19 is a global health problem including Indonesia. This was initiated from the information of the World Health Organization (WHO) on 31 December 2019 there was a case of a cluster of pneumonia with a new etiology in Wuhan City, Hubei Province, China and later expanded beyond China. On 30 January 2020, COVID-19 was set to become the public health Emergency of International Concern (PHEIC). On 11 March 2020, COVID-19 was designated as a pandemic. Indonesia first reported 2 positive cases on March 2, 2020 and a positive case continued to increase (Kementrian Kesehatan RI, 2020a). Until April 25, 2020, Indonesia already reported 8. 211 Positive cases, 689 cases died, 1.002 cases recovered from 50,563 people examined with the results of the examination is 42,352 negative. (Susilawati, 2020).

This study discusses how to support vulnerable isolated citizens during the COVID-19 lockdown situation through a collaborative community initiative that engages with community network actors. The authors focus on how social capital can enhance engagement with local community members to achieve the goal.

The current COVID-19 lockdown situation has had an impact on people's connectedness by limiting their allowed behaviours, resulting in a negative impact on 
people's mental health and well-being on the whole (Oe, 2020). The enhancement of human interaction and networking to sustain people's mental health has been on the emergent agenda during the current COVID-19 situation.

To tackle this issue, one theory that could be employed is the efficacy of community members' engagement, as discussed by McMillian and Chavis (1986), who proposed a 'sense of community' model. This model suggests four main dimensions that should be increased to demonstrate commitment to community members and support vulnerable people: a sense of belonging, an emotional connection, fulfilment of needs, and influence (Bermea et al., 2019).

It seems to have been agreed upon that a creation of collaborative initiatives can contribute to solving community issues. The current COVID-19 lockdown situation is critically influencing citizens' well-being; it has a particularly big impact on vulnerable isolated people in terms of stress and uncertainty. In this paper, we focus on community members' interaction and engagement with Information Communication Technology (ICT) as an instrument to enable smooth information sharing and consensus building in the community. At the same time, the positive impact of assistive technologies enhances connectedness among people on the virtual community paradigm.

\section{Review of Literature}

\subsection{Placemaking as a Platform for Nurturing a Sense of Community}

Placemaking is a multi-faceted approach for creating value for local places. Placemaking can enhance a local community's attractiveness and brand, which contributes to better community development. It has been a main point of policy agenda for both central and local governments, and recently, the contribution of the collaborative input from local stakeholders has been discussed as one of the key factors to sustain communities (Franklin \& Marsden, 2015; Lepofsky \& Fraser, 2003; Markusen \& Gadwa, 2010).

Until now, in research on the theme of how to collaborate with community members to solve societal issues, the sense of community (SOC) model has been applied to cases to analyse how to promote engagement of citizens to reach a targeted goal (Bermea et al., 2019; McMillian \& Chavis, 1986); there has also been research that expects charitable organisations and social enterprises to exert their functions and specialties to achieve the aim (Oe, 2015; Ridley-Duff \& Bull, 2019; Weeks \& Oe, 2020). As the flow of examining measures to encourage participation in community building has acknowledged, implementation of ICT to accelerate the development of social capital can serve as a basis for SOC and robust local communities (Brown, 2001; Ko et al., 2019; Sweet et al., 2020).

Weeks and Oe (2020) have discussed how to fulfil community needs based on a model that matches needs with supports through a community ICT network. This takes the theoretical theme of how to create a participatory society a step further. In line with this approach, it has also been discussed that a community's potential needs and supports could be discovered by utilising simplified systems with assistive technologies to analyse big data that is then collected and archived in the community (Hosseini et al., 2019; Takemoto \& Ota, 2017).

Placemaking by governments and other community actors can enhance a community's brand with (1) improvements of housing and town aesthetics, (2) better quality of infrastructure (e.g. roads, transportations, secured stable public utilities, the internet network), and (3) better balanced socio-economic characteristics (e.g. a good balance of old and new residents, acceptance of diversified ethnicities, sustainable planning in the long term) (Weeks 
$\&$ Oe, 2020). These actions discussed in the context of placemaking provide us with a key idea that community network stakeholders, such as residents, businesses, charities and other specialised organisations, can be motivated to commit to developing their communities. To enhance a variety of stakeholders to lead the initiatives in the community requires clarification of how to review and evaluate their activities and the effectiveness and outcomes of the processes (Tanimoto, 2019). It is also crucial to support these initiatives with assistive measures, such as ICT implementation, training and enhancing mutual learning perspectives.

Governments and relevant public sectors are the main actors in a community who have the authority to develop societal, economic and cultural values in the area (Creagh et al., 2020). However, the effect of placemaking can stimulate collaborative actions among community groups who can contribute to reimaging of these places. An inclusive approach with local community actors in the reimaging process can produce more values and impact than those made if the reimaging process was conducted only by the government. Therefore, placemaking can be used as a catalyst to enhance co-value creation, not only to attract inward investment (Huang \& Roberts, 2019).

Due to the tight financial conditions of many governments, enabling sustainable placemaking requires contributions from community groups. As societal members of the community, stakeholders, such as businesses, social enterprises, charities and other members, should share their resources to support community development. In doing so, government placemaking can trigger the strengthening of social bonding among groups and encourage various contributions from community groups, including both economic and non-economic contributions. This concept has been supported by research conducted in various cultural and geographical contexts (Chen \& Qu, 2020; Dabaj \& Conti, 2020; Huang et al., 2019; Skop et al., 2019).

\subsection{A Key Player: Social Enterprise as a Catalyst for a Collaborative Milieu}

Social enterprises have business models that aim to profit by solving social issues in various ways. Common discussion of this model has included opportunities for socially diverse groups that have not been supported in the market, inviting inputs and contributions from different network actors embedded in the local community (Alter, 2007; Bull \& RidleyDuff, 2019; Fowler et al., 2019; Lee, 2015; Nasruddin et al., 2014).

Bull (2018) presented a basic framework of social enterprise perspectives referring to the relational actors, who emphasised the key role of redistributing the state and the reciprocity of communities. They also proposed the development of a holistic paradigm with a transcendental approach including the state/local communities or public/private, forprofit/not-for-profit and formal/informal businesses. As Arif \& Yuhdi (2020) discussed, thinking skills in the context of solving community issues could be a critical factor, for instance, an intense learning of critical learning with scaffolding support including ICT application at the universities would be helpful.

\section{Discussion}

Moreover, to enable the collaborative network to function smoothly involving relevant stakeholders requires well balanced human resource planning in every single organisation (Mansaray, 2019). Inline with this critical point, Suswati et al. (2020) discussed and demonstrates a pathway how to engage human resources embedded in the community using a live case study of university students' involvement. Figure 1 represents the relational network actors who support collaborative actions. 


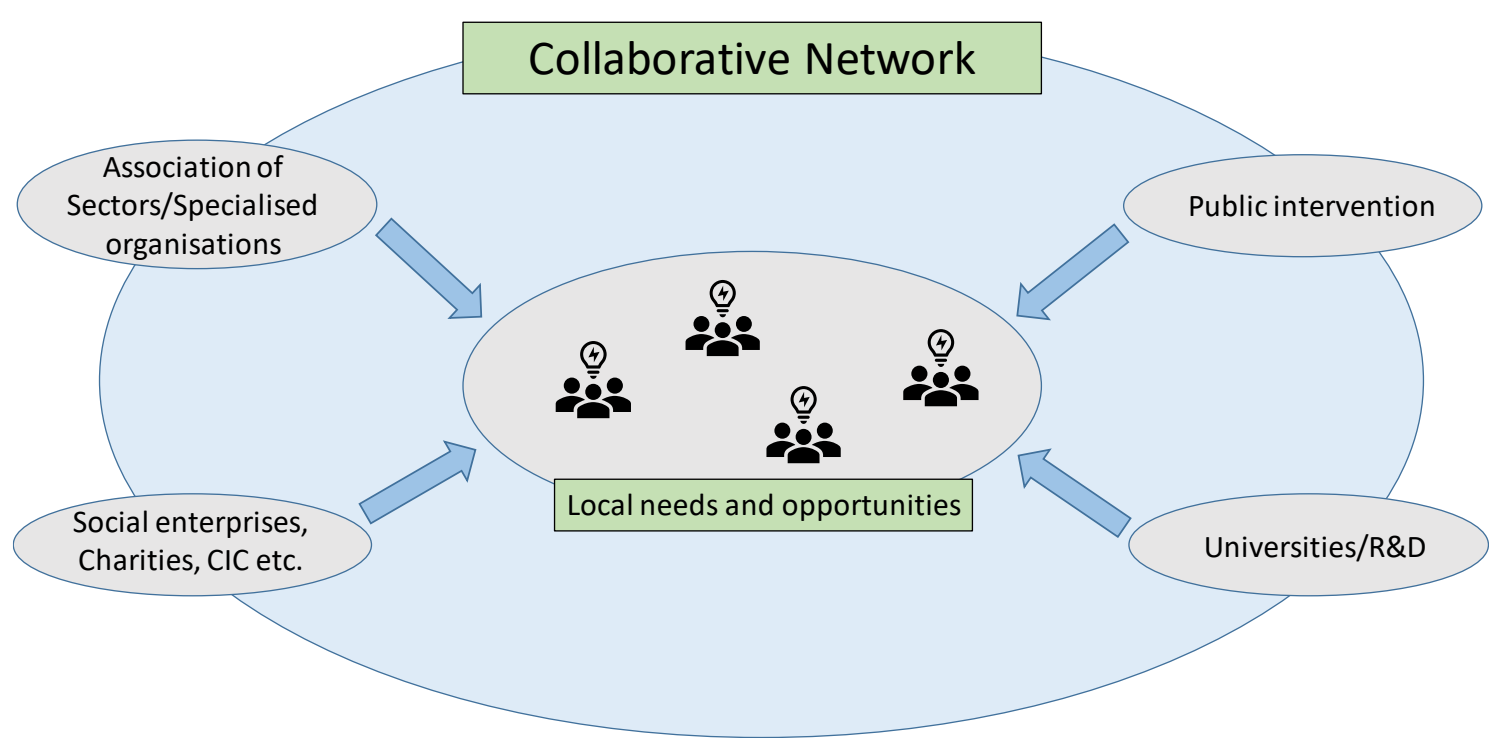

Figure 1 Collaborative milieu including network actors

\subsection{Social Capital as a Community-Bonding aDhesive}

Phelps and Hassed (2012) discussed that social capital accumulated in communities has an influence on reducing community crimes and negative incidents that affect the well-being of residents. Oe (2005) summarised that an inclusive social network has a positive effect on solving social issues and problems. She also suggested the implementation of ICT measures to share the aim and values among the relevant stakeholders, which can accelerate collaborative actions taken to achieve the community goal.

Cigler and Joslyn (2002) discussed how social capital effects a relationship between group involvement and political tolerance, implying that it has a catalytic power to include and engage local community members with a community project to achieve a shared aim.

\subsection{Ubiquitous Network Perspectives}

Based on the existing literature, an analytical framework has been developed, Figure 2 is developed. This relationships with steps demonstrate the key actors and the interactive actions in co-value creation that sustain communities with assistive ICT measures sharing the information. As Jafar and Rahmayani (2020) discussed, the Industrial Era 4.0 or millennial era which have penetrated into various aspects of our life has enhanced the potential positive impact of the ICT implementations.

Moreover, in enhancing collaborative engagement requires some 'scaffolding approach' to support active learning in the course of collaboration to achieve a shared goal. Bing-quan et al. (2020) suggested that clear image of potential business opportunities could be a trigger for enhancement of engaging the stakeholders in the initiative. They also presented key themes how to involve local community members such as young entrepreneurs and university students to secure the entrepreneurial behaviour quality. 


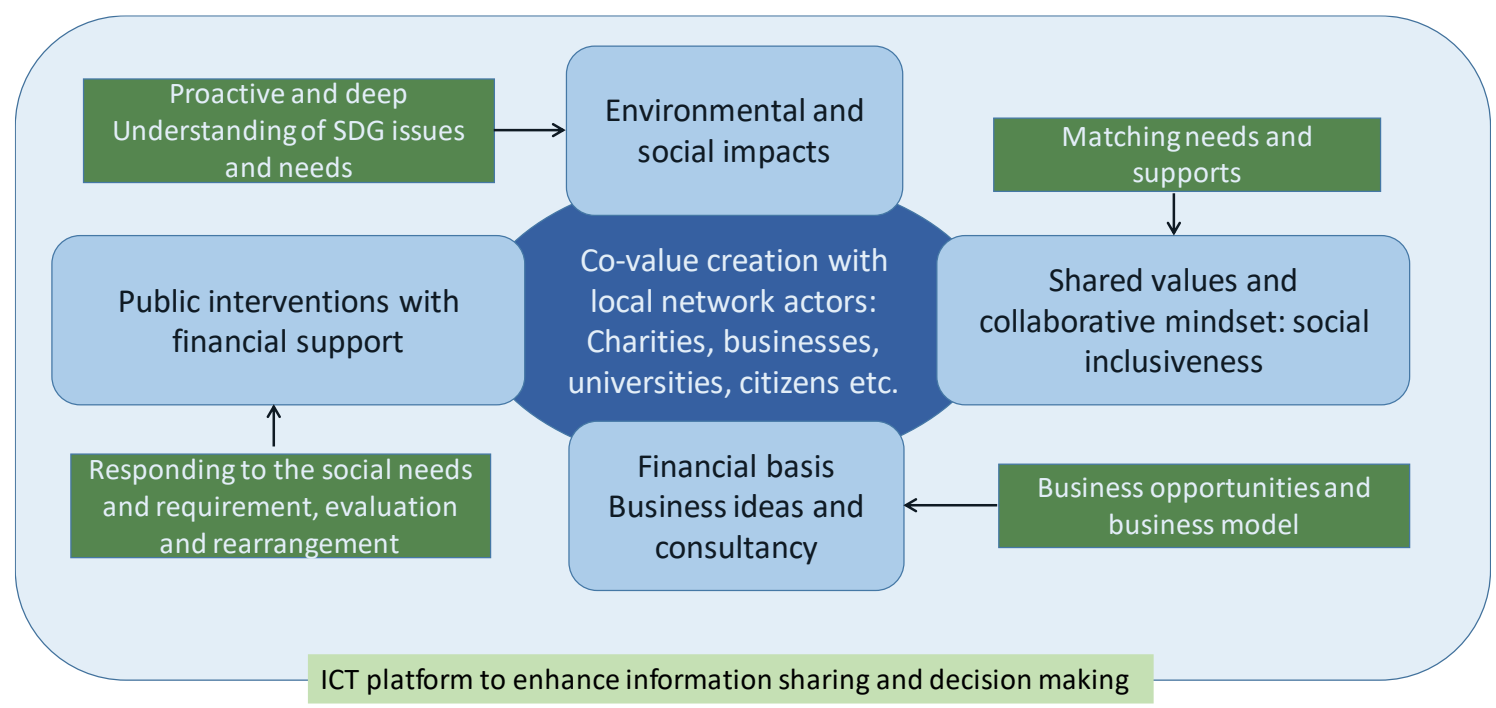

Figure 2 Inclusive model for co-value creation (inspired by Bacq and Janssen (2011) and rearranged by the authors)

\subsection{Initiative for a Ubiquitous Network Community}

Based on the discussion so far, it is time for us to propose a discussion paradigm of how to support vulnerable isolated citizens during the lockdown situation. As Oe (2020) discussed, how to enhance social connectedness and communication should be the key point in sustaining people's mental well-being, and remote or virtual measures can seal this critical gap to reconnect isolated citizens on a virtual platform. As Foth et al. (2011) suggested, citizens engaged with social networks can trigger the enhancement of a collaborative community with the philosophy of supporting each other. Some more meso-level discussions focusing on building cities as virtual communities have been carried out and proposed by interdisciplinary researchers already (Anthopoulos et al., 2009; Salim \& Haque, 2015), and other contemporary themes, such as the Internet of Things and big data, have also attracted researchers and practitioners, since they are potential factors behind building ubiquitous communities (Lu et al., 2019; Sun et. al., 2016).

Social enterprises and other stakeholders are expected to take a catalytic role in inviting the involvement of other local community members, including private sector/mainstream businesses, the voluntary sector (i.e. charities) and the government. Westall (2001) also discussed the role of key players who support the interactive space in enhancing collaborative work in the community. Figure 3 demonstrates an image of Ubiquitous network community involving local community members. 


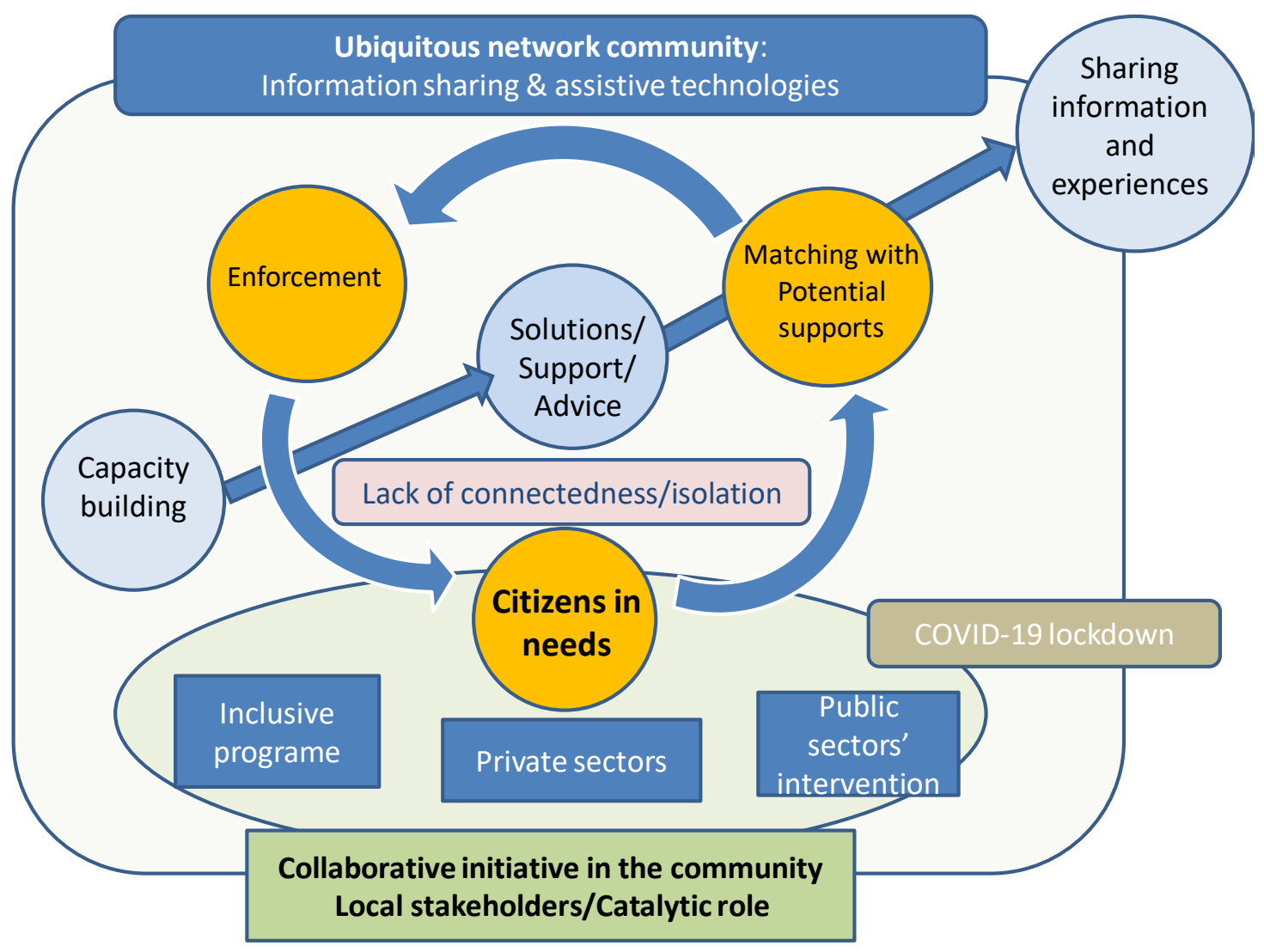

Figure 3 Ubiquitous network community to support isolated vulnerable citizens (inspired by Baez-Camargp and Jacobs (2011) and the authors' collection)

\section{Conclusion}

As noted, this conceptual study has explored the applicability and usefulness of ICT implementation for ubiquitous networks to support vulnerable isolated citizens, based on collaborative community initiatives. The exploration into the impact of ICT and engaging catalytic stakeholders in communities should also be coordinated to provide support that match the needs of vulnerable citizens during the COVID-19 lockdown situation.

This research aimed to build an analytical framework which will support the expansion of the further academic discussion inviting interdisciplinary researchers and practitioners to support vulnerable isolated citizens in the difficult COVID-19 outbreak. This research is planned as an initial trigger for a collaborative research platform focusing on the UN Sustainable Development Goals (e.g. good health and well-being; industry, innovation and infrastructure; partnerships for goals), which will also provide a co-creation and coproduction paradigm to respond to societal issues that arise beyond COVID-19.

The proposed framework needs to be verified and applied to current community issues to develop actionable implications for community stakeholders. In doing so, the analytical agenda should be narrowed down to specific ICT issues, including standardisations. For instance, research can be collaborated with the multi-lateral policy dialogue at the UN's specialised organisation, the International Telecommunication Union (ITU), focusing on coordinating global standards that contribute to harmonised communities, even during the COVID-19 situation. According to the ITU, 'telecommunication standards provide the 
technical foundations of the global ICT ecosystem, binding together the rich diversity of ICT networks, devices and services that have become so essential to business and daily life' (2020).

The lessons we have been learning and the things we have been experiencing during the difficult situation of lockdown have to be passed on from generation to generation to support each other by building robust connected communities based on ICT power; we should embrace the challenges of a complex transition to this higher sphere for the good of us all.

\section{References}

Alter, K. (2007). Social enterprise typology. Virtue ventures LLC, 12(1), 1-124.

Anthopoulos, L., \& Fitsilis, P. (2009, September). From online to ubiquitous cities: The technical transformation of virtual communities. In International Conference on eDemocracy (pp. 360-372). Springer, Berlin, Heidelberg.

Arif, S., \& Yuhdi, A. (2020). Integration of High Order Thinking Skills in Research Method Subject in University. Britain International of Linguistics Arts and Education (BIoLAE) Journal, 2(1), 378-383.

Auerbach, C., \& Silverstein, L. B., 2003. Qualitative data: An introduction to coding and analysis (Vol. 21). NYU press.

Bacq, S., \& Janssen, F. (2011). The multiple faces of social entrepreneurship: A review of definitional issues based on geographical and thematic criteria. Entrepreneurship \& Regional Development, 23(5-6), 373-403.

Baez Camargo, C., \& Jacobs, E. (2011). A framework to assess governance of health systems in low income countries, Working Paper Series, 11. Available from https://edoc.unibas.ch/66329/ Accessed 3 May 2020.

Barraket, J., Eversole, R., Luke, B., \& Barth, S. (2018). Resourcefulness of locally-oriented social enterprises: Implications for rural community development. Journal of Rural Studies.

Bermea, A. M., Lardier Jr, D. T., Forenza, B., Garcia-Reid, P., \& Reid, R. J. (2019). Communitarianism and youth empowerment: Motivation for participation in a community-based substance abuse prevention coalition. Journal of community psychology, 47(1), 49-62.

Bing-quan, L., Rong, H., Hai-xin, D., \& Xu-dong, Z. (2020). Analysis on Behavior Factors of Successful Entrepreneurship of College Students of Local University in Guangdong Province. Britain International of Humanities and Social Sciences (BIoHS) Journal, 2(1), 35-44.

Brown, R. E. (2001). The process of community-building in distance learning classes. Journal of asynchronous learning networks, 5(2), 18-35.

Bull, M. (2018). Reconceptualising social enterprise in the UK through an appreciation of legal identities. International Journal of Entrepreneurial Behavior \& Research, 24(3), 587-605.

Bull, M., \& Ridley-Duff, R. (2019). Towards an appreciation of ethics in social enterprise business models. Journal of Business Ethics, 159(3), 619-634.

Canady, V. A. (2020). NAMI New Hampshire maintaining community connectedness. Mental Health Weekly, 30(16), 4-5.

Chen, Y., \& Qu, L. (2020). Emerging participative approaches for urban regeneration in Chinese megacities. Journal of Urban Planning and Development, 146(1), 04019029. 
Cigler, A., \& Joslyn, M. R. (2002). The extensiveness of group membership and social capital: The impact on political tolerance attitudes. Political Research Quarterly, 55(1), $7-25$.

Creagh, R., Babb, C., \& Farley, H. (2020). Local Governments and Developers in Placemaking: Defining Their Responsibilities and Capacities to Shape Place. In Placemaking Fundamentals for the Built Environment (pp. 107-128). Palgrave Macmillan, Singapore.

Dabaj, J., \& Conti, R. L. (2020). Placemaking in Lebanese Cities Hosting Displaced Communities. The Journal of Public Space, 5(1), 219-246.

Defourny, J. and Nyssens, M. (2016), "Fundamentals for an International Typology of Social Enterprise Models". Voluntas, Vol. 28, No 6, pp. 2469-2497

Duniam, M., \& Eversole, R. (2013). Social Enterprises and Local Government: A Scoping Study, Australian Centre of Excellence for Local Government, Sydney.

Edmonds, W. M., 2019. Snowballing: A Qualitative Study Using Snowball Sampling. SAGE Publications Ltd.

Edwards, R., and Holland, J., 2013. What is qualitative interviewing? A\&C Black.

Etzioni, A. (2011). Citizenship in a communitarian perspective. Ethnicities, 11(3), 336-349.

Foth, M., Forlano, L., Satchell, C., \& Gibbs, M. (Eds.). (2011). From social butterfly to engaged citizen: Urban informatics, social media, ubiquitous computing, and mobile technology to support citizen engagement. MIT Press.

Fowler, E. A., Coffey, B. S., \& Dixon-Fowler, H. R. (2019). Transforming good intentions into social impact: A case on the creation and evolution of a social enterprise. Journal of Business Ethics, 159(3), 665-678.

Franklin, A., \& Marsden, T. (2015). (Dis) connected communities and sustainable placemaking. Local Environment, 20(8), 940-956.

Hare-Duke, L., Dening, T., de Oliveira, D., Milner, K., \& Slade, M. (2019). Conceptual framework for social connectedness in mental disorders: Systematic review and narrative synthesis. Journal of affective disorders, 245, 188-199.

Hosseini, M., Angelopoulos, C.M., Chai, W.K. and Kundig, S., 2019. Crowdcloud: a crowdsourced system for cloud infrastructure. Cluster Computing, 22 (2), 455-470.

Huang, S. M., \& Roberts, J. L. (2019). Place-Making. The Wiley Blackwell Encyclopedia of Urban and Regional Studies, 1-5.

ITU (2020) International standardization in virtual space: ITU's decisive response to COVID-19, Available at https://news.itu.int/international-standardization-virtual-spacecovid-19/ [Accessed 8 May 2020]

Jafar, M., \& Rahmayani, I. (2020). Reconstruction of Renewal of Community Development Methods in the World of Islamic Education in the Industrial 4.0 Era. Britain International of Humanities and Social Sciences (BIoHS) Journal, 2(1), 82-89.

Lu, X., Hinkelman, K., Fu, Y., Wang, J., Zuo, W., Zhang, Q., \& Saad, W. (2019). An open source modeling framework for interdependent energy-transportation-communication infrastructure in smart and connected communities. IEEE Access, 7, 55458-55476. 
Mansaray, H. E. (2019). The Consequence of Human Resource Planning on Organizational Performance: An Ephemeral Review. Britain International of Humanities and Social Sciences (BIoHS) Journal, 1(2), 50-61.

Markusen, A., \& Gadwa, A. (2010). Creative placemaking. Washington, DC: National Endowment for the Arts.

McMillan, D. W., \& Chavis, D. M. (1986). Sense of community: A definition and theory. Journal of Community Psychology, 14, 6-23.

Nasruddin, E., Misaridin, F., \& Aulia, N. (2014). Innovation for a social enterprise business model: An analysis of key success factors, International Journal of Organizational Innovation, 7. 149-157.

Oe, H (2005) Empirical studies of social networks and the rehabilitation of stagnated communities, Graduate School of Information and Telecommunication Studies, Waseda University, Available at http://gitsdb.jp/bulletin/2005/2005papers/2005dissertation_12_oe.pdf [Accessed 17 March 2020]

Salim, F., \& Haque, U. (2015). Urban computing in the wild: A survey on large scale participation and citizen engagement with ubiquitous computing, cyber physical systems, and Internet of Things. International Journal of Human-Computer Studies, 81, $31-48$.

Schultze, U. and Avital, M., 2011. Designing interviews to generate rich data for information systems research, Information and organization, Vol. 21 No. 1, pp. 1-16.

Skop, E., Bose, P., Hackworth, J., \& Kaplan, D. H. (2019). Navigating Ethnicity: Segregation, Placemaking, and Difference. The AAG Review of Books, 7(1), 68-76.

Tanimoto, K. (2019). Do multi-stakeholder initiatives make for better CSR?. Corporate Governance: The International Journal of Business in Society.

Tetnowski, J., 2015. Qualitative case study research design. Perspectives on Fluency and Fluency Disorders, 25(1), pp.39-45.

Weeks, M. and Oe, H. (2020) Is placemaking used by governments only to attract inward investment?, Field-based research on enhancement of inclusive community with diversified network actors [Discussion Paper Series: 2020-2]

Westall, A. (2001), Value-led, Market Driven. London: Institute Public Policy Research. 